\title{
Agile Fitness of Software Companies in Bangladesh: An Empirical Investigation
}

\author{
M M Mahbubul Syeed ${ }^{1}$, Razib Hayat Khan ${ }^{2}$ \\ Professional Member \\ $\mathrm{ACM}$
}

\author{
Jonayet $\mathrm{Miah}^{3}$ \\ North-South University \\ Bangladesh
}

\begin{abstract}
With the mandate of light-weight working practices, iterative development, customer collaboration and incremental delivery of business values, Agile software development methods have become the de-facto standard for commercial software development, worldwide. Consequently, this research aims to empirically investigate the preparedness and the adoption of agile practices in the prominent software companies in Bangladesh. To achieve this goal, an extensive survey with 16 established software companies in Bangladesh is carried out. Results exhibit that the Scrum agile methodology is the highest practiced one. Alongside, to a great extent these software companies have the readiness to effectively adopt the Scrum methodology. However, with regard to practicing the Scrum principles, they fall short in many key aspects.
\end{abstract}

Keywords-Agile manifesto; agile methodology; scrum; software development projects; software companies in Bangladesh

\section{INTRODUCTION}

For the past two decades, agile software development methods have becoming the de-facto standard worldwide for developing cutting age software systems [1]. Several variations of this method, e.g., Scrum, Extreme Programming, Crystal, FDD and others have attracted a lot of attention to the software engineering and research communities.

A group of agile practitioners, loosely known as Agile Alliance formulates the agile principles in 2001 [1]. These principles, popularly termed as Agile Manifesto, help to optimize the software development process and increase efficiency with greater customer satisfaction [2]. The Agile Manifesto provides the four core values for software development projects [1][2], namely, (a) Individuals and interactions over processes and tools, (b) Working software over comprehensive documentation, (c) Customer collaboration over contract negotiation, and (d) Responding to change over following a plan. Therefore, agile principles shifts the software development paradigm from plan-driven to value-driven process models [1][3].

Based on the agile manifestation, all agile methodologies at their very core implements rapid and iterative development process for continuous and incremental software delivery, have flexibility to accommodate changing requirements and market demands, and integrate customer feedback [5][7].

Statistics on the adoption and usage of Agile methods to run software development projects has shown overwhelming acceptance worldwide [18] [19]. It has been reported that around $70 \%$ of the companies, practice agile methods for software development[18]. According to 1015 developers around the world, agile practices are the integral part of their everyday activities [18]. Other studies, reported that agile projects are $28 \%$ more successful than traditional projects [19]. Alongside, in the USA, the average salary of an agile project manager is more than USD 90K [19].

Bangladesh being an emerging economy is rapidly extending Her presence in the world software market with a current market value of USD 130 billion [20]. In recent decade, several of Her software companies has accomplished a number of outsourced projects and thereby gaining reputation [20] [21]. With reference to this, the software companies in Bangladesh must demonstrate the authentic adoption and practice of Agile principles, norms, and practices to persuade their international clients and extend their market share even further.

This research aims to find out the extent to which the prominent software development companies in Bangladesh follow the Agile principles. Consequently, the primary contributions of this research is as follows: (a) empirically investigate into the Agile development practices in the context of established software companies located in Bangladesh, (b) analyze and comprehend the fitness of these software companies in relation to Agile practices, and (c) offer guidelines / scope of improvements based on the standards defined by Agile manifesto. Alongside, this reporting also assist the overseas cooperates to decide on outsourcing projects in Bangladesh.

This paper is organized as follows, in Section II the background work and focus of this study is presented, Section III detail the realization of the survey method for conducting this study. Result and recommendations are presented in Section IV. Finally, overall assessment, future works and concluding remarks are drawn in Sections V and VI, respectively.

\section{BACKGROUND AND RESEARCH FOCUS}

Agile software development principles are initially proposed and promoted by a group of 17 software professionals popularly known as the Agile Alliance [3]. They stated principles, norms, and practices for a set of lightweight software development methods in the form of Agile Manifesto [4] [3]. Thereafter, several Agile methods have been matured and put into practice. Among then, Scrum [5], Extreme Programming (XP) [6], Feature Driven Development (FDD) [12], Crystal [6], Lean Software Development [7], and Kanban [8], are the most common methods in the software industries [9].

Agile methods follow light-weight working practices, continuous development and delivery, integration of changing requirements and customer collaboration throughout the development process, over long-planning, cumbersome documenta- 
tion, and inflexible development phases [10]. Therefore, these methods ensure high customer satisfaction through the delivery of business values in short iterations and incrementally with the option of accommodating changing needs even late within the development process [11] [4] [3].

Since their emergence, agile methods are used by more than $70 \%$ companies in their software development projects [18] [19]. Therefore, research related to the adoption and practice of agile methodologies in software companies has been the center concern in software engineering research. In [16], a survey based comparative study was conducted to find out the most popular agile methodologies practiced in the industries. Result suggests higher popularity of Scrum than that of Extreme Programming and Kanban. Alongside, the applicability and implication of agile development methods were investigated in [17].

In [13], an approach to effectively adopt agile methods, specially, Scrum is presented. A survey based research was conducted in [14] to formulate the challenges for enterprises to adopt agile methods. Reported results highlighted that there is no single agile method that can be universally applied, and have to be tailored to integrate into existing processes. On the track, a framework termed Agile Software Solution Framework were proposed and empirically verified to assist the companies in defining and introducing agility in the development process [15].

However, to the best of our knowledge, no comprehensive investigation has been reported to verify the extent to which software companies adopt and practice the agile principles, specially concerning the developing countries, e.g., Bangladesh.

Therefore, the primary focus of this research is three fold: (a) empirically investigate into the Agile development practices in the context of established software companies located in Bangladesh, (b) analyze and comprehend the fitness of these software companies in relation to Agile practices, and (c) offer guidelines / scope of improvements for these companies based on the standards defined by Agile manifesto. Alongside this reporting also support the overseas cooperates to decide on outsourcing projects to Bangladesh.

\section{RESEARCH APPROACH}

To conduct this research, an extensive survey is carried out with the established software companies based in Dhaka city, the capital of Bangladesh. The Survey Research Method is the best suited for a research of this nature, because, it is a comprehensive method for collecting information to describe, compare or explain knowledge, attitudes, and behavior on a given domain [22][23].

The target audience of our survey is the software professionals of different ranks who are currently employed in various prominent software companies in Bangladesh. A total of 38 professionals participated in the survey from 16 different companies, a taxonomy of which is discussed in Section IV-A.

1) Survey construction: To construct the survey, four agile methods that are most practised in software firms in general are selected [9]. These methods are, Scrum [5], XP [6], FDD [12] and Crystal [6]. Thereafter, based on the mandate and practices of each of the methods, specific set of questionnaires are designed. These questions further grouped into focused domains to better comprehend on the actual realisation of the methods within the companies. The questionnaire for Scrum method is detailed in Section VI (Fig. 14). For the other methods the questionnaires are omitted as they are not that popular according to our survey findings (discussed in Section IV-B). Alongside, to get the company and employee profiling, a common set of questions are also designed.

The questions have both close ended and open ended options to respond. The close ended options are developed in frequency scales, rather than two-point Yes/No scale. The usage of frequency scale has enabled to measure how frequently an event occurs when following a specific agile method. Furthermore, it helps to conduct statistical analysis from the data. The answer options for which frequency scale is used contained four options, they are: none, rarely, sometimes, all the time. The optional open ended part, allows the interviewee to complement their answer through the narrative expression.

The questions are kept short, to the point and unambiguous. Each question focuses on one aspect of the Agile method only. In formulating the questions, standard terms specific to each of the methods are used for greater clarity and understanding. Additionally, each question is associated with legends to further explain the content of the questions.

2) Survey execution : To execute this survey, an interactive Google form is designed with the questionnaire. This form is accompanied with the detail guidelines to assist the interviewees and navigate through the questionnaire session. The form begins with a common section to record company profile followed by four specific selections for the four selected methods. Based on the interviewee selection of the method, the corresponding method related questionnaire section is opened. Response is recorded in Google sheet categorically which is then extracted and analysed. To complete the survey, approximately 10 to 15 minutes of dedicated time is required.

The design of this survey is cross-sectional and are aimed at a fixed point of time. All the companies are contacted well before conducting the survey through official channel, and a Non Disclosure Agreement (NDA) was signed to maintain the secrecy and anonymity of the company specific information. The NDA also guarantee to some extent the accuracy of responses as the interviewee feels confident of not getting disclosed. Then the contact information (official emails and phone numbers) of the interviewees from each of the companies are collected. The survey form is sent over the email with clear guidelines and a follow up phone conversation is carried out in case of any clarification is required by the participant.

3) Evaluation approach: The survey instrumentation as prescribed above supports both quantitative and qualitative analysis on the collected data. The first part of the answer (frequency scale answers) allowed to get a generic perspective on a given aspect (e.g., Do all the team members work in the same space?) through quantitative investigation. To achieve this, related data are aggregated, grouped and charts are generated. The second part of the answer (i.e., the optional open ended response) is analyzed, comprehended and mapped with the corresponding charts to draw critical reasoning on the overall response. Once done, this assessment is verified against the 


\begin{tabular}{|c|c|c|c|c|}
\hline Firm & Year Est. & Age (Y) & Company Focus & Certification \\
\hline \multirow[t]{2}{*}{ Firm A } & 2001 & 19 & Product: HR systems, Banking solutions. & ISO 9001 \\
\hline & & & Service: Customer centric services & \\
\hline \multirow[t]{3}{*}{ Firm B } & 1998 & 21 & Product: HR systems, Banking \& Financial solutions, E-commerce, E- & CMMIL- 5 \\
\hline & & & learning systems, Mobile applications & ISO 9001:2008 \\
\hline & & & Service: Testing as a service & \\
\hline \multirow[t]{2}{*}{ Firm C } & 2001 & 19 & Product: IoT, Big Data, Deep Learning, Financial, Blockchain. & CMMI level 3 \\
\hline & & & $\begin{array}{l}\text { Service: Offshore services, Application management as a service, Testing } \\
\text { and automation }\end{array}$ & ISO 9001 \\
\hline \multirow[t]{2}{*}{ Firm D } & 2006 & 14 & Product: Banking solutions, Machine learning Al and cloud solutions, E- & ISO 27001: 2013 \\
\hline & & & commerce sites, Game development, AR and VR systems & 9001: 2015 \\
\hline \multirow[t]{2}{*}{ Firm E } & 2004 & 16 & $\begin{array}{l}\text { Product: Mobile Application (IOS and Android), Management software, } \\
\text { Game development }\end{array}$ & ISO $9001: 2008$ \\
\hline & & & Service: Export software products overseas & \\
\hline Firm F & 2001 & 19 & Product: Healthcare systems, Banking solution, Management systems. & \\
\hline Firm G & 2003 & 17 & $\begin{array}{l}\text { Product: Mobile and Embedded applications for sectors like, } \\
\text { entertainment, banking, insurance, pharmaceutical, telecommunication }\end{array}$ & \\
\hline \multirow[t]{2}{*}{ Firm H } & 2000 & 20 & Product: E-commerce sites, Banking solutions & ISO 9001:2008 \\
\hline & & & Service: Largest internet service provider & \\
\hline Firm I & 2010 & 10 & Product: Mobile applications, E-commerce sites, Management systems & \\
\hline \multirow[t]{2}{*}{ Firm J } & 2003 & 17 & $\begin{array}{l}\text { Product: Mobile applications, Enterprise telecommunication solutions, } \\
\text { E-governance, NLP, Machine learning }\end{array}$ & \\
\hline & & & $\begin{array}{l}\text { Service: Operates in Singapore, Bangladesh, India, UK, USA, and Hong } \\
\text { Kong }\end{array}$ & \\
\hline Firm $\mathrm{K}$ & 2010 & 10 & $\begin{array}{l}\text { Product: Mobile applications, E-commerce sites, Desktop software, } \\
\text { Digital marketing. }\end{array}$ & \\
\hline \multirow[t]{2}{*}{ Firm L } & 2015 & 5 & Product: Ridesharing platform, Food, Parcel, Courier services. & \\
\hline & & & Service: Fastest-growing tech startups in Asia. & \\
\hline \multirow[t]{2}{*}{ Firm M } & 2006 & 14 & $\begin{array}{l}\text { Product: Content management, Web applications, E-commerce sites, } \\
\text { Game development, Project management and Accounting software. }\end{array}$ & \\
\hline & & & Service: Network monitoring and Administration & \\
\hline \multirow[t]{2}{*}{ Firm $\mathrm{N}$} & 2009 & 11 & $\begin{array}{l}\text { Product: Mobile applications, Full-stack web development, Enterprise } \\
\text { database design, UX/UI design }\end{array}$ & \\
\hline & & & Service: Providing full-stack resources to clients worldwide. & \\
\hline Firm 0 & 2017 & 3 & Product: Web development, Mobile Application, Digital Marketing & \\
\hline Firm P & 2012 & 8 & Product: Business software, ERP, HR management & \\
\hline
\end{tabular}

Fig. 1. The brief Portfolio of the Companies.

standard practices of the methods to derive recommendations.

4) Survey reliability: To ensure the reliability of the survey instrument, the so called test-retest approach is used. That is, the same respondents are surveyed once again at different point of time to observe the variation on the response.

\section{ANALYSIS AND SYNTHESIS}

This survey is conducted among 16 prominent software companies located in Dhaka city, the capital of Bangladesh. A total of 38 techno-professionals currently employed in these companies at different ranks have participated in this survey. In the following sections the transcript of evaluation is presented.

\section{A. On the Company Profiling}

The first part of the survey questionnaire is designed to get an overall portfolio of the software companies, especially focusing on their project focus, achieved standardisation, technology expertise, employee and project profiling. This taxonomy of company portfolio is required to assess the overall preparedness of the companies to carry out agile development while maintain all the key parameters to meet standard and quality [3] [9].

The brief portfolio of the 16 software companies is presented in Fig. 1. These companies have an average operational experience of 13.5 years with a maximum of 20 years and a minimum of 3 years (Column 2 and 3 of Fig. 1). There are 6 companies who already achieved ISO certification with two of them attaining Capability Maturity (CMM) level of 3 and 5 (Column 5 in Fig. 1). The average operational experience of these 6 companies is 18.2 years, therefore having a long trail of successful software project accomplishment. Their client base includes both local and international corporate and enterprises.

During their service life, most of these companies developed their expertise on both product development as well as service delivery on diverse categories, a classification of which 


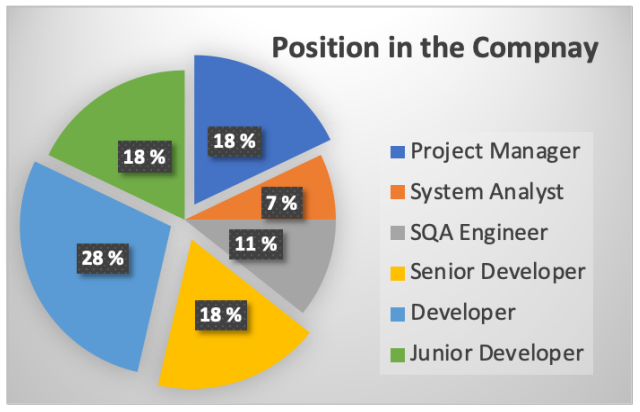

(a)

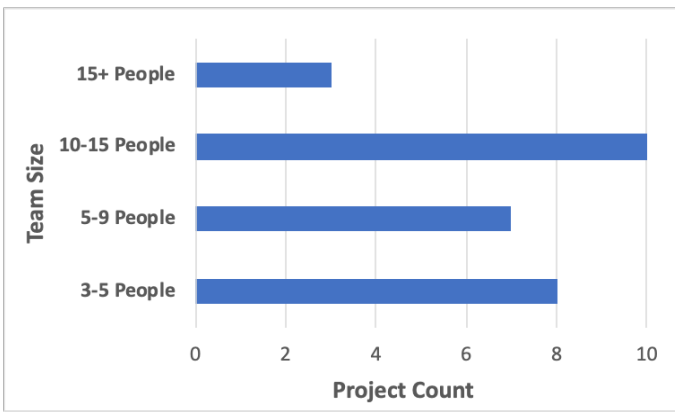

(b)

Fig. 2. (a) Employee Ranks and (b) Project Team Size within the Companies.

is presented in Fig. 3(a). According to this figure, E-commerce and Web services are the core focus followed by Management and Banking solutions. This observation is in line with the market demand [24]. Alongside, the mobile application and game development are cited as a major emerging market segment for these companies.

Accomplished projects have a development lifetime of either 3 to 6 months (very short to short duration), or $1 / 2$ to 1 year (medium duration) or more than a year (long duration), depending on the requirements. A distribution of the projects along this lifespan reveals that $75 \%$ of the projects belong to medium and long duration with only $25 \%$ are from short duration. Additionally, the data support that the short duration projects are mostly performed by the new companies in the list having less than 10 years of experience in the field. Fig. 3(b) summarizes this observation.

All the companies offering a number of ranks to their employees that are typical for an established software development company to carry out their projects. According to the survey, 6 such ranks are offered, namely, Project Manager, System Analyst, SQA Engineer, Senior Developer, Developer, and Junior Developer. Fig. 2(a) narrates these ranks in a descending order with the proportion of each rank within the companies (calculated based on the total number of employees per rank in the 16 companies). As a reference to the reader, the Project Manager is the administrative lead for project planning, monitoring and managing the progress and resources. The Systems Analyst is the IT guru who is responsible to analyze the problem domain and to come up with the best approach in solving it. The Senior Developer is the highly experienced professional who lead a team of developers in getting the development work done. The Developer is responsible for messing up their hands with implementing the code by following best practiced design patterns. Part of their responsibility includes training and assigning development tasks to Junior Developers and assist them. Finally, the $S Q A$ Engineer is responsible for designing and executing the test plan and assist the development team to resolve them [25][26].

According to the statistics, the rank distribution has $18 \%$ as Project Manager, $7 \%$ as System Analyst and $18 \%$ as Senior developers. Therefore, a $43 \%$ of the total manpower belongs to expert professionals. The working force consumes $46 \%$ share with Developers and Junior developers having $28 \%$ and $18 \%$, respectively. This distribution matches the ideal manpower distribution that an established software company should have [26][27].

Alongside, the formation of the development team with respect to number of people involved in a project, adheres to the standard of agile practices [28]. Fig. 2(b) shows the typical formation of teams in the last 28 projects that are completed by these companies. As per this statistics, 9 projects had 5-9 people which is the standard for projects of medium duration, and 13 projects had either $10-15$ people or $15+$ people which is the conventional choice for large projects. Therefore, the companies are often guided by the standards when it comes to the matter of involving adequate manpower to the deserving projects. This is one of core concern in project management to ensure quality product development [30] [29].

Finally, the selection and use of contemporary tools and techniques play a pivotal role in practicing agile methodologies and ensuring the quality product development. With the growing adoption of agile practices over the past couple of decades, a number of tools become the de-facto integral part of them. This includes, for instance, the version control systems (e.g. Git, GitHub), project management tools (e.g., Burn down charts, Jira) and project specific technologies (e.g., frameworks and languages), among others. The survey summary on this concern is shown in Fig. 4. Around $90 \%$ of the companies use Git as a version control system, and $60 \%$ of them use UML as a tool for technical design. Among the frameworks, web, ASP .net and app specific frameworks are used. This outcome is also inline with the project focus of the companies. However, professional project management and tracking tools are not used that frequently.

\section{B. On the Agile Practice of the Software Companies}

This research selected four Agile methods for the survey, namely, Scrum, XP, FDD and Crystal. These methods are selected based on their popularity in use. However, according to the survey response none of the companies ever used Crystal method for their projects, therefore, discarded from the discussion. Among the other three methods, Scrum is reported as the highest practiced method ( $82 \%$ of the companies use it) with XP and FDD having usage percentage of $4 \%$ each. Again due to very low response for XP and FDD, this research lacks sufficient empirical data to comprehensively assess the 


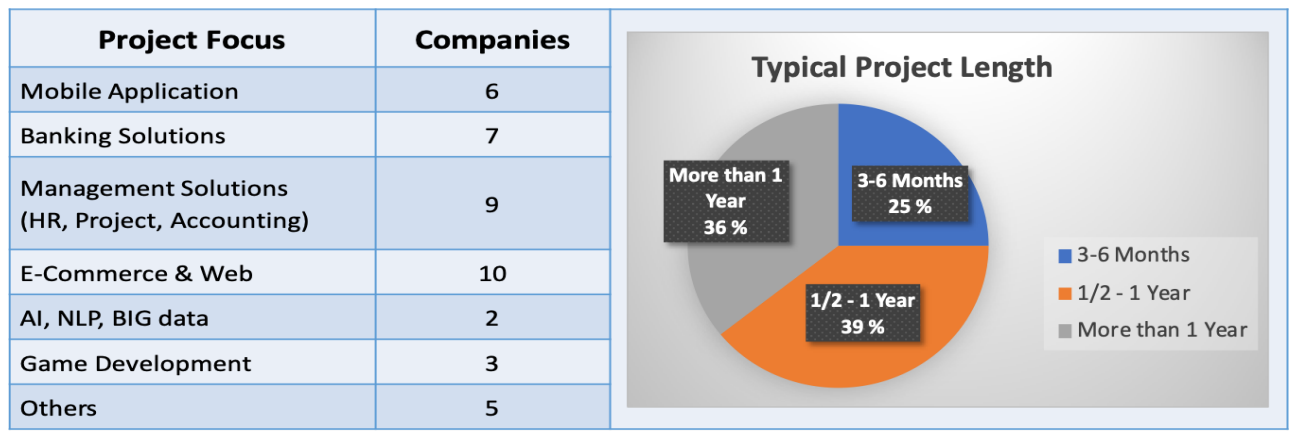

(a)

(b)

Fig. 3. (a) Project Focus and (b) Typical Project Length of the Companies.

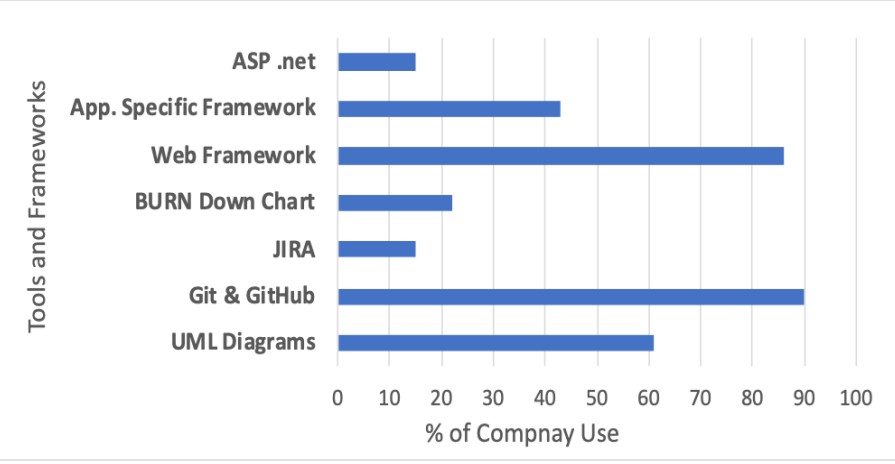

Fig. 4. Tools and Technologies used by the Companies.

adoption of these two methods. Therefore, exempted from further discussion.

In the following section a detail evaluation of the Scrum method is presented in relation to its' adoption and practice within the selected software companies. Additionally, acquired evidences and statistics are examined against the method to trace the followings, (a) the extent to which current practices resembles the standards, and (b) verify the preparedness of the companies in carrying out the projects by leveraging the method.

\section{Scrum as a Development Method}

Scrum as an agile method is the most popular development method according to this survey. $82 \%$ of the surveyed companies have adopted this method to carryout their development projects. To gain maximum insight on the topic, 16 questions in four distinct categories concerning the Scrum method are asked. These categories are, Team (2 Questions), Artifacts (5 Questions), Role (2 Questions) and Process (6 Questions). Fig. 14 details this question set.

The Scrum Team should be assessed by their physical location and the team size for individual projects. The response on these concerns are highlighted in Fig. 5(a) and (b). As stated in the Scrum principles [5], the scrum team should be located in the same physical premises to maximize the effective communication among the team members for rapid development. However, in unavoidable circumstances, team members can be geographically distributed and collaborating over online. The survey reported that majority of the software firms are well within this recommendation (Fig. 5(a)). 53\% of the companies always have on premises team with $31 \%$ sometimes. Only those companies that have off-shore sites have distributed teams (11\%).

On the team size, Scrum practice suggested the standard should be seven, plus or minus two [5], having the range between 5 to 9 members. This number includes the Scrum Master, Product owner and the Developers. A team smaller than this recommendation may find it arduous to accomplish enough in each sprint, whereas for larger teams communication becomes complex and cumbersome [26][31]. The survey response (Fig. 5 (b)) reported that only $48 \%$ of the companies maintain the recommended team size of 5 to 9 members, and the rest $(52 \%)$ have either undersized or oversized team. Therefore, the companies must reassess their team formation with proper justification of performance and output produced.

Within the Scrum practices, two key responsibilities are to anchoring the daily meeting (a brief meeting held daily with the scrum team to synchronize development activities) and the scrum review meeting (a meeting held at the end of each sprint to assess the passing sprint and set goals for the next sprint) [32]. According to Scrum standard, the Scrum Master is the person who plays the Role of the anchor for these meetings. However, both the meetings (i.e. daily meeting and scrum review meeting) must be duly conducted by the Team Members [32]. Fig. 6(a) and (b) summarizes the survey outcome on this concern.

It is observed that in case of $70 \%$ of the companies, the Scrum Master is responsible for holding the daily review meeting whereas in $18 \%$ and $3 \%$ cases held by the team members and daily trackers, respectively (Fig. 6(a)). In case of Sprint review meeting, mostly Scrum master (53\%) leads the meeting with $25 \%$ cases held by the team members and daily trackers (Fig. 6(b)). Therefore, it can be affirmed that in most part the companies adheres to the scrum mandate in maintaining the roles of the scrum team. Albeit, there are few companies who are involving the Product owner to anchor the designated meetings, which is neither desirable nor recommended by Scrum. Therefore, requires further explanation and rectification.

The Scrum method leveraged several means or Artifacts to 


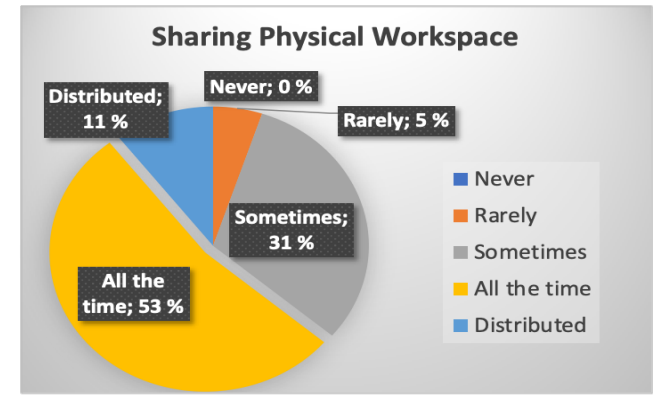

(a)

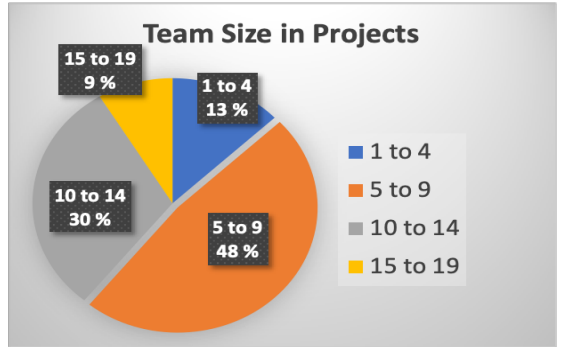

(b)

Fig. 5. Response on (a) Sharing Physical Space and (b) Project Team Size.

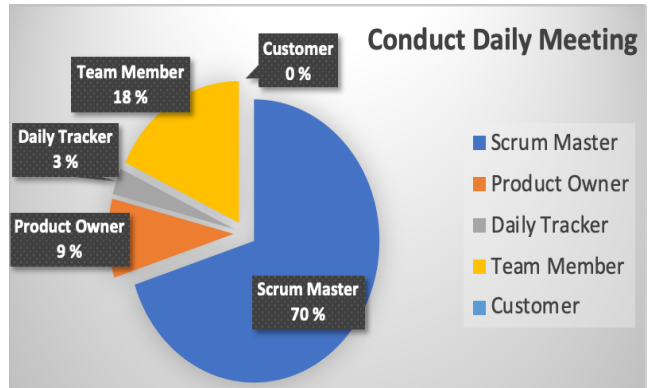

(a)

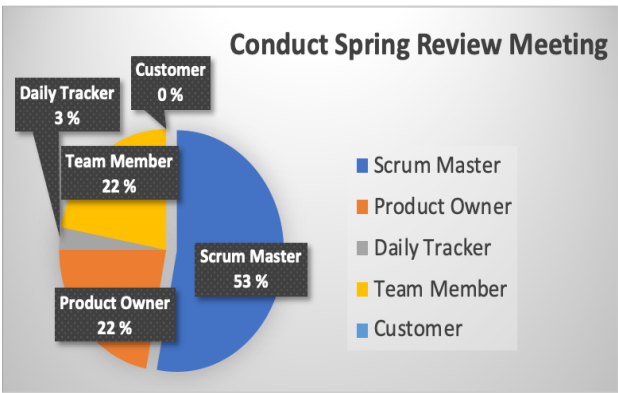

(b)

Fig. 6. The Team Member Responsible for Conducting (a) The Daily Meeting and (b) The Scrum Review Meeting

carryout the development activities. This includes for example, maintaining and following Product Backlog, Sprint Backlog, Burndown chart, among others. Companies practicing Scrum method should adopt and utilize these artifacts for efficacious product development [26] [5]. The survey outcome on this concern is summarized in Fig. 7(a), (b) and 8(a).

For reference, the Product Backlog describes the work to be done that will add value to the completed product. It is dynamic in nature to capture what are the most important features to be developed next. Therefore, the scrum master should constantly update and refine the Product Backlog to keep it aligned with market demand [32]. Whereas, the Sprint Backlog depicts the product increment to be implemented and added to the already done product at the end of current Sprint [31]. It should define two things: the "What to be developed" of the Sprint and the "How to develop" of the Sprint. It therefore, contains the blue print for the developers of how they will deliver the product Increment and realize the Sprint Goal [32].

The survey result on the use of backlog (either, Product or Sprint backlog) is detailed in Fig. 7(a). According to this reporting, about half of the companies (44\%) use them for estimating the future requirements, $26 \%$ use them to prioritize the requirements and others, to record the requirements (13\%) or to record the status (13\%). However, according to practice, all these activities should be part of utilization of these backlogs [31].

The other core Scrum artefact is the Burndown chart, which is a graphical representation of work left to do over the project time [32]. This chart plots the outstanding work on the 'y-axis' with project time along the ' $\mathrm{x}$-axis'. This visual representation helps the team to constantly monitor the project scope creep, and keep development work on schedule. This chart must be updated in the daily scrum meeting. However, the survey result on use of this chart differs largely with the proposals, as shown in Fig. 7(b). Only, $21 \%$ of the companies always use this chart $(17 \%)$ or its' third-party variants $(4 \%)$. Majority of them either rarely $(70 \%)$ or never $(9 \%)$ use it. Therefore, it is a major concern form Scrum perspective and the companies must put serious effort on adopting this tool as an integral part of their development practices.

In the realm of Scrum practices, using the above listed artefacts share the same goals. Those are, to maximize transparency through highly visible real-time picture of what is being done, and a shared understanding of the work in progress [26]. Therefore, these artifacts must be openly available to all the team members to see, discuss, follow and update to synchronize the rapid development activities [31]. The surveyed companies also adhere to this practice of making artefacts openly accessible to all the team members, either always (78\%) or sometimes (22\%) (Fig. 8(a)).

The Scrum Process defines the agile project management methodology for rapid development of a quality software product. This involves carrying out several activities by employing the team members in different roles and effective utilization of the artefacts. The core scrum activities includes, defining and updating the sprint backlog for a given sprint, holding the scrum meeting, sprint planning meeting and sprint review meeting, code integration and testing, and system demonstra- 


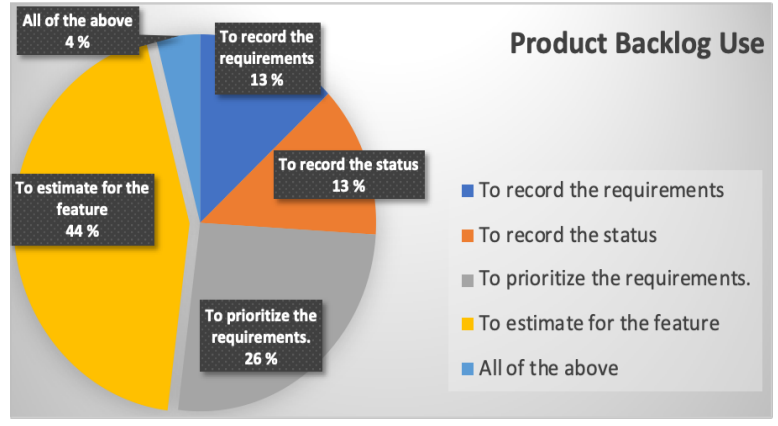

(a)

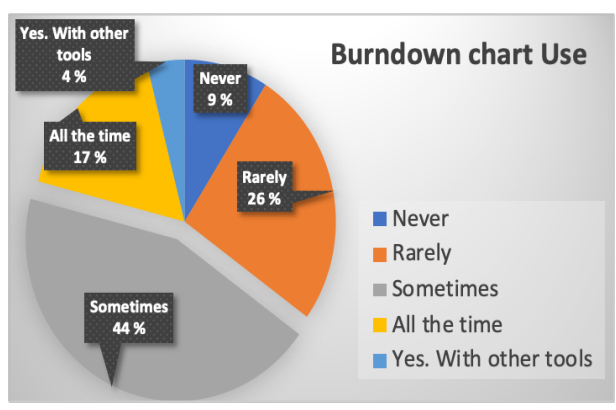

(b)

Fig. 7. Use of (a) Product Backlog and (b) Burndown Chart.

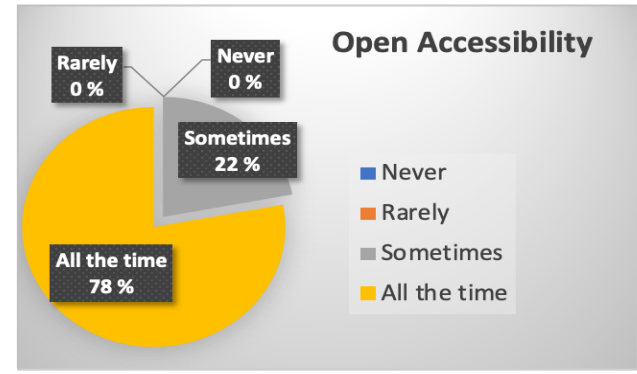

(a)

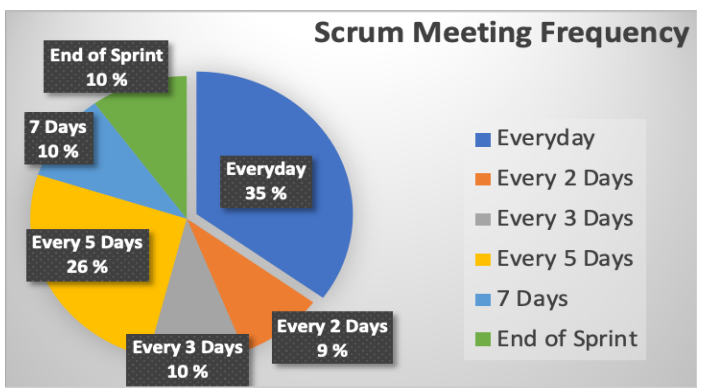

(b)

Fig. 8. (a) Accessibility of the Artifacts and (b) Scrum Meeting Frequency.

tion.

According to the methodology [31], a Scrum meeting is 15-minute time-boxed event that should be held each day of a sprint with the whole team. Inline with this recommendation, the survey response (Fig. 8(b)) exhibit that all the companies hold scrum meeting. However, the meeting is hold according to their own defined intervals, which varies from the daily meeting (35\%), to holding it in every two days $(9 \%)$, or in every 3 days (10\%), or in 5 days (26\%), 7 days (10\%) and even at the end of sprint $(10 \%)$. This statistics highly contradicts with the core value of agile practices and the scrum. Because, a sprint is usually lasts for 7 days with a sprint backlog to be implemented. Therefore, holding scrum meeting daily is an inevitable need for the development to progress smoothly. However, $65 \%$ of the companies are not realizing the fact, and therefore, suffers from absorbing the core essence of scrum. Consequently, this reporting calls for further investigation and rectification in the process.

The Sprint backlog for a given sprint consists of a list of tasks selected from product backlog to be completed within the sprint [32]. As the sprint length is short and development goes rapid, the Sprint backlog should be updated once each day by the Scrum Master and the burndown chart is updated to keep every team member in sync [31]. Adoption of these practices within the surveyed companies are shown in Fig. 9(a) and (b).

Reporting on the Sprint backlog update frequency (Fig. 9(a)) reveals three distinct trends, namely, daily (only $40 \%$ of the companies adopt this), between 2 to 7 days (36\% of the companies follow this), and only with client requirement change (22\% of the companies). Therefore, companies have to revise their understanding and practice on this particular concern. However, in $88 \%$ of the companies either the Scrum Master $(40 \%)$ or a designated team member $(40 \%)$ is responsible to update the backlog (Fig. 9(b)), which is well within the scrum convention.

Among the other core tasks, conducting Sprint Planning and Sprint review meetings with the involvement of the Product owner is highly recommended. Fig. 10 and 11 details the survey outcome on these practices. According to the Scrum guide, the Sprint Planning meeting is held at the beginning of each sprint to set the sprint backlog. The Sprint Review meeting is held at the end of a Sprint to inspect whether the backlog is implemented accordingly. Among the other stakeholders, the Product Owner must be present in the meetings to prioritize the most important features to be implemented and verified [26].

Majority of the companies $(61 \%)$ agrees that they always hold the sprint planning meeting with $34 \%$ respond with either sometimes or rarely (Fig. 10(a)). In defining the length (or duration) of a Sprint, $48 \%$ companies maintains the highly recommended 7 days window, whereas, 38\% responds with either 14 or 30 days duration and $14 \%$ says its' depends on the project. At large, neither of these statistics follows the recommendation, and is a violation of the core practices of Scrum methodology. 


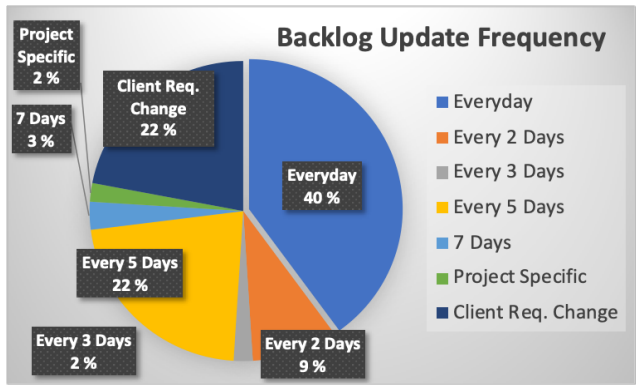

(a)

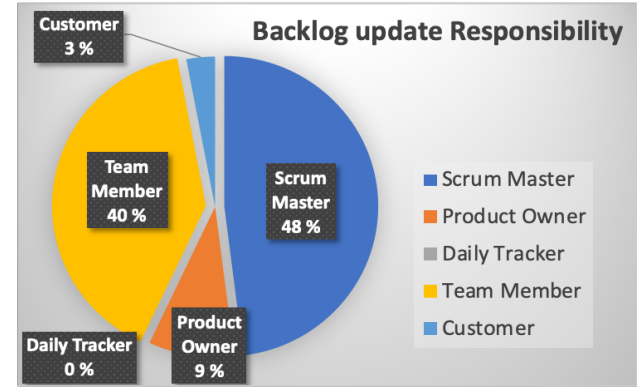

(b)

Fig. 9. (a) Sprint Backlog update Frequency and (b) Person Responsible to do the Update.

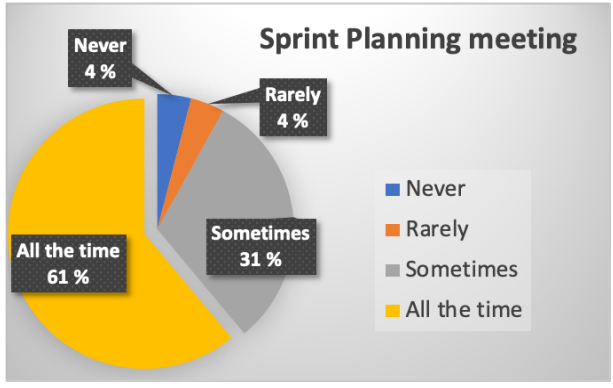

(a)

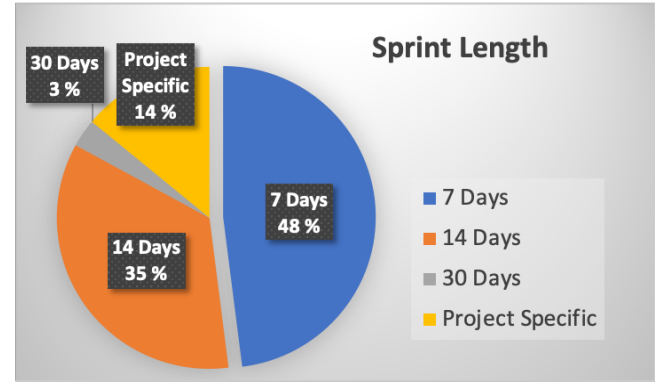

(b)

Fig. 10. (a) Holding of Sprint Planning Meeting and (b) Typical Length of a Sprint.

However, $70 \%$ of the companies responded positively in relation to hold the Sprint review meeting always (Fig. 11(a)), with $30 \%$ either sometimes or rarely holding the meeting. Therefore, companies are better performing in relation to this core activity of scrum. The Product owner is rarely attending either of the meetings according to the survey outcome (Fig. 11(b)). With the fact that the attendance of Product owner is highly recommended in the sprint meetings, only $9 \%$ of companies acknowledge their presence all the time. For the rest $(91 \%)$ it is either sometimes, rarely or never. This outcome also point to the fact that the product owner in Bangladesh might lag the technical competencies or the client companies are reluctant to involve their representatives to cut cost. Whatever may be the reason, this lagging in participation is detrimental to overall process adoption and to the quality of the software produced [32].

Scrum methodology like other agile practices relies on continuous code integration on the daily basis [31]. Integration testing must go hand-in-hand with the daily integration [31]. However, the survey outcome shows a large deviation with this standard practice. As can be seen from Fig. 12(a), only $44 \%$ companies adheres to daily integration and testing, while majority have their own defined schedule.

Finally, developed system (either at the end of each sprint or at the end of the project) is demonstrated practically by executing it [32], rather using any means of formal presentations (e.g., power points, oral or visualization). According to the survey response (Fig. 12(b)), majority (57\%) follows the convention of demonstrating the system practically, while others use undesirable methods.

\section{Overall Assessment}

The overarching assessment of the survey outcome highlights both competencies and weaknesses of the software companies in relation to Agile fitness. The taxonomy of the company portfolio reveals strong competencies to adopt and practice agile development methods (as discussed in detail in Section IV-A). The overall operational experience, range of software product development and service delivery expertise, the formation of the development team, the selection and use of contemporary tools and techniques, strongly support this claim. Therefore, it can be affirmed that

\section{To a great extent the software companies in Bangladesh have the readiness to effectively practice Scrum methodology.}

Among the Agile methodologies, the Scrum method has overwhelming utilization in the software companies (82\%) in Bangladesh. This selection reflects the most prevalent choice worldwide, as $70 \%$ software companies goes by the Scrum method [25]. However, the critical assessment of the survey statistics on the actual adoption of Scrum practices (as detailed in Section IV-B) reveals that

\section{At large, the software companies in Bangladesh fall short to comply with the Scrum principles.}

Fig. 13 summarises the Scrum fitness of the companies derived from the survey results. In this figure, the approval / adoption rate (in $\mathrm{X}$-axis) of companies are shown against the recommended Scrum practices (in Y-axis). 


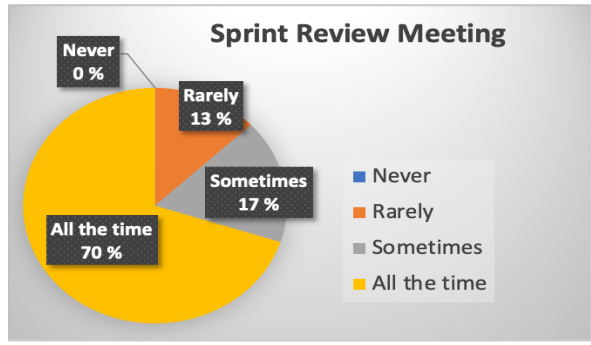

(a)

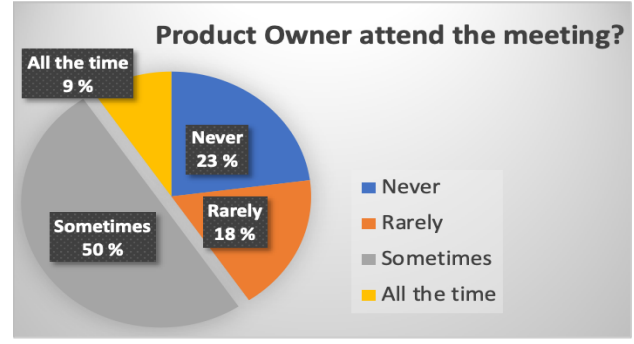

(b)

Fig. 11. (a) Holding Sprint Review Meeting and (b) Attendance of Product Owner in the Sprint Planning and Review Meetings.

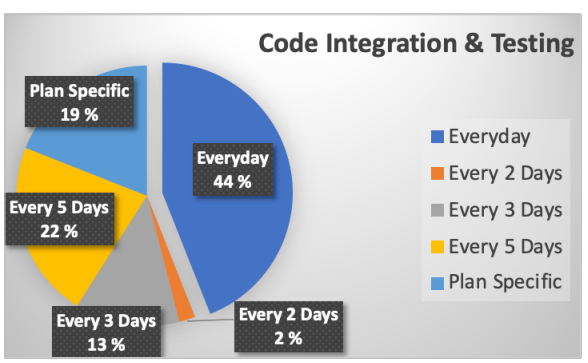

(a)

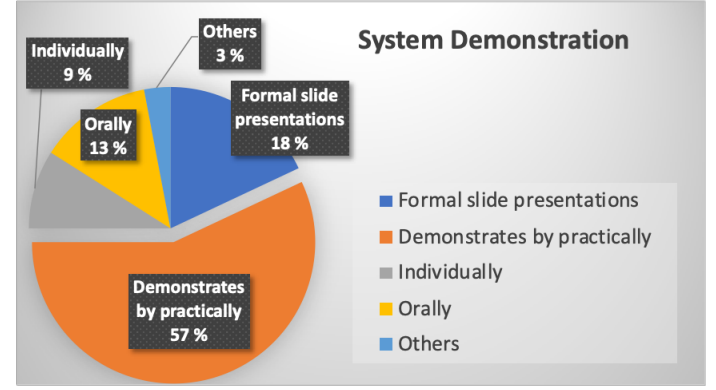

(b)

Fig. 12. (a) Code Integration and Testing Frequency, (b) Method used for System Demonstration.

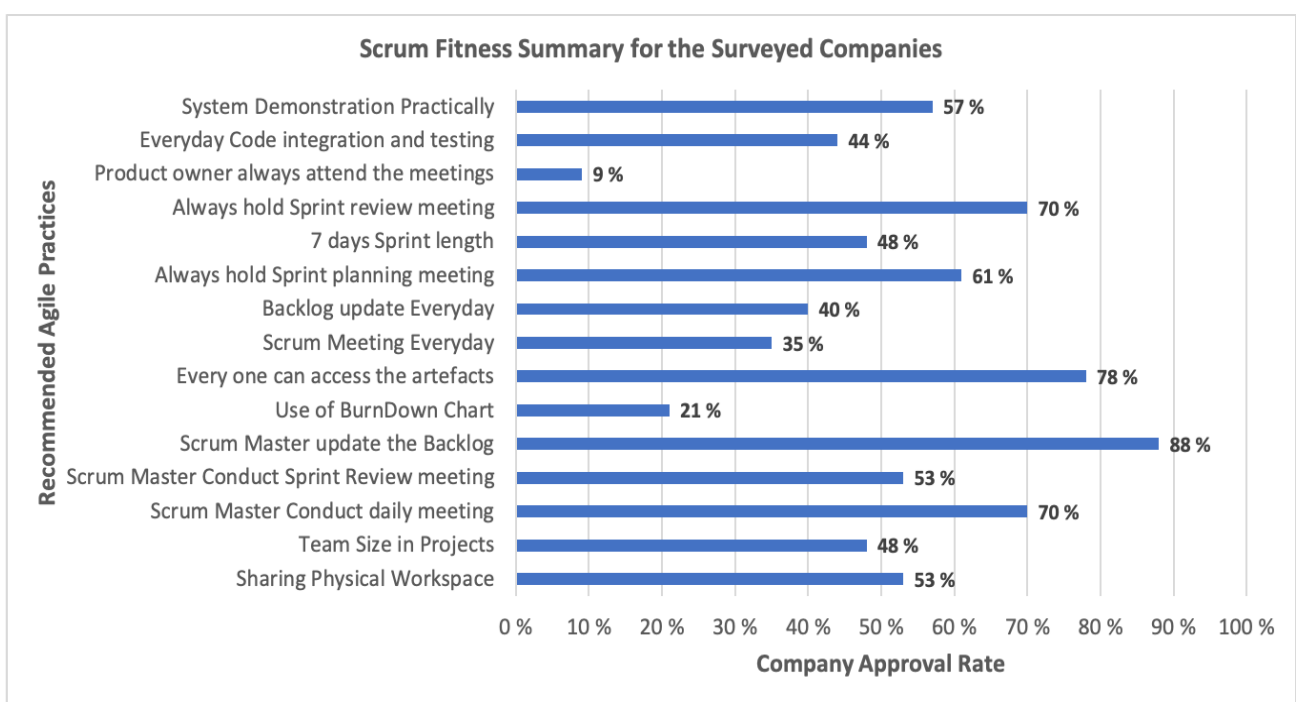

Fig. 13. Scrum Fitness overview for the Surveyed Companies.

According to the summary report in Fig. 13, the approval rate is around $50 \%$ or bellow for most of the key practices of Scrum. For some practices the rate is critically low which is alarming. For instance, integrating the product owner in the meetings is only $9 \%$ which on the contrary is one of the highest priority practices to be adopted [32]. Additionally, use of burndown charts or similar tools for constantly tracking the project progress and keep all the stakeholders in synchronized is only $21 \%$. For the other practices along with the above two, the adoption rate need to be improved. This study recommences the companies to employ agile experts external to the company to investigate into the issues, identify core areas of improvement and a pragmatic course of actions to meet the Scrum standard [31].

\section{CONCLUSION}

This research carried out an empirically investigation on the agile software development practices within the context of established software companies in Bangladesh to (a) define the readiness and fitness of these companies in relation to Agile practices, and (b) formulate the scope of improvements based on the agile standard. It is reported that the Scrum agile 
method is the highest practiced one among the four, which is an assertion of the typical selection worldwide. Alongside, the overarching outcome reveals that the companies have the preparedness in practicing the Scrum method in fullest. However, with regard to practicing Scrum principles, they fall short severely in many key factors. Therefore, the future research should dug deep into the cause of these shortcomings and formulate guidelines accordingly for the process improvement.

\section{SCRUM MeTHOD QuestionnAIRE}

Scrum Questionnaire Set (Fig. 14).

\section{REFERENCES}

[1] Eva-Maria Schön, Jörg Thomaschewski, María José Escalona, Agile Requirements Engineering: A systematic literature review, Computer Standards \& Interfaces, Volume 49, 2017, Pages 79-91.

[2] E.M. Schön, M.Escalona, J.Thomaschewski, Agile Values and Their Implementation in Practice,International Journal of Interactive Multimedia and Artificial Intelligence, 3 (61), 2015.

[3] Misra, S., Kumar, V., Kumar, U., Fantazy, K. and Akhter, M. (2012), Agile software development practices: evolution, principles, and criticisms, International Journal of Quality \& Reliability Management, Vol. 29 No. 9, pp. 972-980.

[4] C. Dewan, R. Jain, and R. Kohli, The Agile Methodology, IJCSMS International Journal of Computer Science \& Management Studies, 12(3), September 2012.

[5] K. Schwaber, M. Beedle, Agile Software Development with Scrum, vol. 1, Prentice Hall Upper Saddle River, 2002.

[6] K. Beck, C. Andres, Extreme Programming Explained: Embrace Change, Addison-Wesley Professional, 2004.

[7] M. Poppendieck, T. Poppendieck, Lean Software Development: An Agile Toolkit, Addison-Wesley Professional, 2003.

[8] D.J. Anderson, Kanban, Blue Hole Press, 2010.

[9] P. Rodríguez, J. Markkula, M. Oivo, K. Turula, Survey on Agile and Lean usage in finnish software industry, in: Proceedings of the ACMIEEE International Symposium on Empirical Software Engineering and Measurement, ESEM '12, ACM, New York, NY, USA, 2012, pp. 139-148.

[10] K. Beck, M. Beedle, A. van Bennekum, A. Cockburn, W. Cunningham, M. Fowler, J. Grenning, J Highsmith, A. Hunt, R. Jeffries, J. Kern, B. Marick, R.C. Martin, S. Mellor, K. Schwaber, J. Sutherland, D. Thomas, Manifesto for Agile Software Development, 2007.

[11] Eetu Kupiainen, Mika V. Mäntylä, Juha Itkonen, Using metrics in Agile and Lean Software Development - A systematic literature review of industrial studies, Information and Software Technology, Volume 62, 2015, Pages 143-163.

[12] S.R. Palmer,M.Felsing, A Practical Guide to Feature-Driven Development, Pearson Education,2001.

[13] D. Duka, Adoption of agile methodology in software development, Information \& Communication Technology Electronics \& Microelectronics (MIPRO), 2013.

[14] Mahanti A. Challenges in Enterprise Adoption of Agile Methods - A Survey. Journal of Computing and Information Technology - CIT 14, 2006, 3, 197-206.
[15] . Qumer, B. Henderson-Sellers, A framework to support the evaluation, adoption and improvement of agile methods in practice, Journal of Systems and Software, 81(11), 2008, Pages 1899-1919.

[16] Gurpreet Singh Matharu, Anju Mishra, Harmeet Singh, and Priyanka Upadhyay. 2015. Empirical Study of Agile Software Development Methodologies: A Comparative Analysis. SIGSOFT Softw. Eng. Notes 40, 1 (January 2015), 1-6.

[17] Nageswara KudaPavan G PPavan G PNaidu KavitaPraneeth Chakka, A Study of the Agile Software Development Methods, Applicability and Implications in Industry, International Journal of Software Engineering and its Applications 5(2), 2011.

[18] J.F. Tripp, D.J. Armstrong. Exploring the Relationship Between Organizational Adoption Motives and the Tailoring of Agile Methods, Hawaii International Conference on System Science, pp. 4799-4806, 2014.

[19] Stapleton, J. DSDM: Dynamic Systems Development Method. Addison, Reading, MA, 1997.

[20] ICT Business Promotion Council Ministry of Commerce, Peoples Republic of Bangladesh, Visited in 2020. http://www.bpc.org.bd/ibpc software_industry.php.

[21] Kumkum Katha, Software Company in Bangladesh Contributing to vision 2021. Visited in 2020. https://www.southtechgroup.com/ software-company-in-bangladesh/.

[22] Jon A. Krosnick, Survey Research, Annual Review of Psychology, Vol. 50, pp. 537-567. 1999. https://doi.org/10.1146/annurev.psych.50.1.537.

[23] Visser, P. S., Krosnick, J. A., \& Lavrakas, P. J. (2000). Survey research. In H. T. Reis \& C. M. Judd (Eds.), Handbook of research methods in social and personality psychology (p. 223-252). Cambridge University Press.

[24] Vartika Kashyap, Best Business Management Software You Should be Using Today. 2020. https://www.proofhub.com/articles/best-businessmanagement-software.

[25] Murat Yilmaz, Rory V. O'Connor, and Paul Clarke. 2015. Software Development Roles: A Multi-Project Empirical Investigation. SIGSOFT Softw. Eng. Notes 40, 1 (January 2015), 1-5.

[26] R. Hoda, J. Noble and S. Marshall, "Self-Organizing Roles on Agile Software Development Teams," in IEEE Transactions on Software Engineering, vol. 39, no. 3, pp. 422-444, March 2013, doi: 10.1109/TSE.2012.30.

[27] Baddoo, N. and Hall, T. (2002), Practitioner roles in software process improvement: an analysis using grid technique. Softw. Process: Improve. Pract., 7: 17-31. doi:10.1002/spip.151.

[28] V. Lalsing, S. Kishnah, S. Pudaruth, People Factors in Agile Software Development and Project Management, Journal of Software Engineering \& Applications (IJSEA), Vol.3, No.1, January 2012 DOI : 10.5121/ijsea.2012.3109.

[29] S. W. Ambler, "Scaling agile software development through lean governance," 2009 ICSE Workshop on Software Development Governance, Vancouver, BC, 2009, pp. 1-2, doi: 10.1109/SDG.2009.5071328.

[30] A. Ahmed, S. Ahmad, N. Ehsan, E. Mirza and S. Z. Sarwar, "Agile software development: Impact on productivity and quality," 2010 IEEE International Conference on Management of Innovation \& Technology, Singapore, 2010, pp. 287-291, doi: 10.1109/ICMIT.2010.5492703.

[31] C. Larman, Agile and Iterative Development: A Manager's Guide. Boston: Addison Wesley, 2004.

[32] K. Schwaber, "SCRUM Development Process," Business Object Design and Implementation, pp. 117-134, 1997. 


\begin{tabular}{|c|c|c|}
\hline $\begin{array}{l}\text { Agile Method } \\
\text { Concern }\end{array}$ & Questions & Answer Options \\
\hline $\begin{array}{l}\text { The Team } \\
\quad \text { Working place }\end{array}$ & Do all the team members work in the same space? & $\begin{array}{ll}\text { 1. Never } & \text { 2. Rarely } \\
\text { 3. Sometimes } & \text { 4. All the time } \\
\text { 5. Other ........................ }\end{array}$ \\
\hline Team size & What is the overall size of a scrum team? & 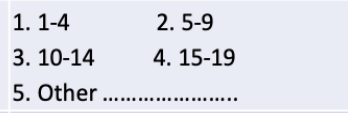 \\
\hline $\begin{array}{l}\text { Artifacts } \\
\text { Artifacts visibility }\end{array}$ & $\begin{array}{l}\text { Are the artifacts (Product Backlog, Sprint Backlog, Burndown chart) openly } \\
\text { accessible and visible to the Scrum Team? }\end{array}$ & $\begin{array}{ll}\text { 1. Never } & \text { 2. Rarely } \\
\text { 3. Sometimes } & \text { 4. All the time }\end{array}$ \\
\hline $\begin{array}{r}\text { Sprint Burndown } \\
\text { Chart }\end{array}$ & Are Sprint burndown charts used to track the progress of the project? & 5. Other .............................. \\
\hline Product Backlog & What is the purpose of the Product backlog in your institution? & $\begin{array}{l}\text { 1. To record the requirements } \\
\text { 2. To record the status } \\
\text { 3. To prioritize the requirements. } \\
\text { 4. To estimate for the feature } \\
\text { 5. All of the above }\end{array}$ \\
\hline Sprint Backlog & How frequently is the Sprint backlog updated? & $\begin{array}{ll}\text { 1. Everyday } & \text { 2. Every } 2 \text { days } \\
\text { 3. Every } 3 \text { days } & 4 \text {. Every } 5 \text { days } \\
\text { 5. Other .............................. }\end{array}$ \\
\hline Updated by & Who updates the Sprint backlog? & 1. Scrum master \\
\hline $\begin{array}{l}\text { Role } \\
\quad \text { Daily Meeting }\end{array}$ & Who conducts daily Scrum meetings? & $\begin{array}{l}\text { 2. Product Owner } \\
\text { 3. Daily Tracker }\end{array}$ \\
\hline Conducted by & Who conducts the sprint review meeting? & $\begin{array}{l}\text { 4. Team member } \\
\text { 5. Customer }\end{array}$ \\
\hline Process & In your institution, are Sprint planning meetings conducted? & $\begin{array}{ll}\text { 1. Never } & \text { 2. Rarely }\end{array}$ \\
\hline $\begin{array}{r}\text { Sprint planning } \\
\text { meeting }\end{array}$ & $\begin{array}{l}\text { Are Product owners and representatives present in the Sprint Planning } \\
\text { Meeting? }\end{array}$ & $\begin{array}{l}\text { 3. Sometimes } 4 \text {. All the time } \\
\text { 5. Other }\end{array}$ \\
\hline Sprint review & $\begin{array}{l}\text { At the end of each Sprint, is there any Sprint review to discuss the progress } \\
\text { of the project? }\end{array}$ & \\
\hline Sprint length & What is the general length of each Sprint? & $\begin{array}{ll}\begin{array}{ll}1.7 \text { days. } & 2.14 \text { days. } \\
\text { 3. } 30 \text { days. } & \text { 4. Over } 30 \text { days. } \\
\text { 5. Other ............................ }\end{array}\end{array}$ \\
\hline Scrum meeting & How frequently are Daily Scrum meetings held? & $\begin{array}{ll}\text { 1. Everyday } \quad \text { 2. Every } 2 \text { days }\end{array}$ \\
\hline Testing the code & How frequently is the code integrated and tested? & 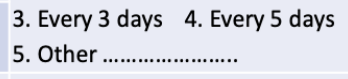 \\
\hline $\begin{array}{r}\text { Demonstration } \\
\text { process }\end{array}$ & How is the developed system demonstrated? & $\begin{array}{l}\text { 1. Formal slide presentations } \\
\text { 2. Demonstrates by practically } \\
\begin{array}{ll}\text { 3. Individually } \quad \text { 4. Orally } \\
\text { 5. Other }\end{array}\end{array}$ \\
\hline
\end{tabular}

Fig. 14. Scrum Method: Questionnaire with Answer Options 